\title{
Antibiotic Regimens in Severe and Acute Purulent Exacerbations of Chronic Bronchitis
}

\author{
A. PINES,* M.D., M.R.C.P.ED.; H. RAAFAT,* D.M., M.R.C.P.GLASG. ; K. PLUCINSKI,* M.D. \\ J. S. B. GREENFIELD,* M.R.C.S., L.R.C.P. ; M. SOLARI, † PH.D.
}

Brit. med. F., 1968, 2, 735-738

Purulent exacerbations of chronic bronchitis are usually treated with antibiotics. Tetracycline, penicillin with streptomycin, and ampicillin are those most often used. Though innumerable courses of these drugs have been given in this illness, no comparative trial of their efficacy has ever been made (Stuart-Harris, 1966). We report a randomized and "blindly" assessed comparison of these antibiotics in hospital inpatients, all of whom were moderately or severely ill.

\section{Pilot Trials}

That antibiotics benefit hospital patients with acute exacerbations of bronchitis is very uncertain. Elmes et al. (1965) compared ampicillin to a placebo and found " no conclusive evidence that ampicillin was beneficial." Johnston (1963) found evidence of benefit in only one out of nine published controlled trials. Similar doubts have been authoritatively expressed (Scadding, 1966 ; Wade, 1967a, 1967b). Thus hospital treatment alone might be as effective as when antibiotics are given as well. The incorporation of a placebo into our trial had to be considered. We thought it wise to assess this first in a pilot trial.

A placebo injection of saline was compared with a combined injection of penicillin three million units and streptomycin $0.5 \mathrm{~g}$., both injections twice daily for 14 days; the streptomycin was stopped on the seventh day. The patients, their conditions of entry to the study, and their "blind" assessments were as in the main trial described below. Allocation was at random. Patients were seen daily by the "blind" assessor; any who deteriorated clinically were at once withdrawn from the trial and promptly treated with high doses of ampicillin, chloramphenicol, or cephaloridine.

By the time 30 patients had been treated we became anxious because more patients had deteriorated than was usual in our experience. After a preliminary analysis and on ethical grounds we ended the pilot trial.

Of the 30 patients 15 had received the antibiotics and 15 the placebo. The two groups were comparable in preliminary features: mean age 66.9 and $68.1 ; 8$ and 7 severely ill ; mean initial fever $99.2^{\circ}$ F. $\left(37.3^{\circ}\right.$ C. $)$ and $99.0^{\circ}$ F. $\left(37.2^{\circ}\right.$ C. $)$; mean white count 12,100 and $12,000 / \mathrm{cu}$. mm. ; mean sedimentation rate 47 and $52 \mathrm{~mm}$. in the first hour; mean peak flow rate 90 and 85 litres/minute; mean $\mathrm{PCO}_{2} 68$ and $71 \mathrm{~mm}$. $\mathrm{Hg}$. All had persistently purulent sputum. General management was identical, as described in the main trial.

Among the group treated with penicillin and streptomycin 10 improved on clinical assessment, in three their state was unchanged, and two deteriorated ; one died. In the placebo group three patients improved, in three their state was unchanged, and nine deteriorated, some severely despite the prompt administration of antibiotics; three died. The sputum became mucoid in 10 patients given chemotherapy, but in only two given the placebo. The temperature was normal by the third day in 13 patients given chemotherapy and in only four given the

- Ware Park Hospital, Herts.

t Chelsea College of Science and Technology, London S.W.3. placebo. Because of the many deteriorations, comparisons of the remaining data at the end of the trial were thought to be invalid. The differences in clinical deterioration and in subsidence of purulence and of fever were significant at the $5 \%$ level $(P<0.05)$. Deterioration was closely correlated with the severity of the illness (six out of seven initially severely ill among the placebo group) and less definitely to a low peak flow rate and high $\mathrm{PCO}_{2}$.

After the disastrous results of placebo treatment it was clearly unjustifiable to incorporate a placebo into our main trial.

Other studies in patients with purulent bronchitis have shown that (1) ampicillin $4 \mathrm{~g}$. daily by mouth was well tolerated and often effective where other antibiotics had failed (Pines, 1964); (2) lymecycline, a derivative of tetracycline, was as effective as tetracycline hydrochloride and gave significantly fewer side-effects in high doses (Pines et al., 1964); and (3) high doses of penicillin were more effective than lower doses combined with streptomycin (Lewis and Pines, 1965). High doses of antibiotics in the first days of treatment are especially important (May, 1965).

\section{Plan of Main Trial}

The regimens compared were:

1. Ampicillin $1 \mathrm{~g}$. four times daily by mouth for 14 days, togetiner with $500 \mathrm{mg}$. intramuscularly three times daily for the first two days.

(2) Lymecycline $612 \mathrm{mg}$. four times daily by mouth (equal to $3 \mathrm{~g}$. daily of tetracycline hydrochloride) for 14 days with $100 \mathrm{mg}$. three times daily intramuscularly for the first two days.

(3) Penicillin three million units twice daily for 14 days accompanied by streptomycin $0.5 \mathrm{~g}$. twice daily for the first seven days.

We considered giving placebo injections twice daily for the remaining 12 days of the trial to those patients receiving ampicillin or lymecycline, comprising two-thirds of the total number, but thought this discomfort was unnecessary and unjustifiable. Instead, the clinical assessments were made independently and "blindly," each observer being completely unaware of individual patients' treatment.

Allocation of treatment was randomized according to Fisher and Yates's tables. Sealed envelopes containing the type of treatment were opened by the admitting doctor in strict numerical order, only after entering suitable patients into the trial. These patients had to fulfil the criteria described below.

The assessment was threefold.

(1) The clinical assessment was made by one of us "blindly" for each patient at the beginning and end of the trial and one and four weeks later. This evaluated obvious changes in degree of well-being, colour, and dyspnoea in two grades of improvement or deterioration and ignored the state of the sputum. Though naturally imprecise, we think this gives a truer picture of the patient's overall state than the investigations detailed below, which can only measure narrow aspects of his illness. 
(2) Sputum was collected over the whole 24 hours daily during the trial period and during the follow-up period of up to one month. It was examined independently and "blindly" for quantity and degree of purulence by an experienced charge nurse. Purulence was measured in the grades recommended by a committee of the Medical Research Council (1965), but in analysis the appearance has been divided into two categoriesmucoid with at the most a trace of pus, or purulent-as minor differences in purulence were of little obvious significance. Three further specimens of sputum were taken early in the morning for naked-eye and bacteriological examinations before and after treatment and when possible one and four weeks later. They were sent by train and special messenger to the laboratory of Dr. J. R. May, Brompton Hospital. Inevitably there were delays in this examination of from 4 to 72 hours after expectoration, depending on when patients were admitted to the triallater in the day, at night, or over week-ends.

(3) Other Assessments.-The peak respiratory flow rate was measured initially and at weekly intervals. A radiograph of the chest, blood sedimentation rate, and white count estimations were obtained, and the capillary $\mathrm{PCO}_{2}$ was measured by Astrupp's method in patients who were severely ill, all on the first and fifteenth days. The temperature was recorded twice daily.

\section{The Patients}

To match the patients entering the trial so far as was possible, all had to fulfil each of the following criteria: (a) over 50 years of age, (b) male, (c) a history of bronchitis for five years or more, $(d)$ a definite history during the past six weeks of an exacerbation of symptoms, $(e)$ moderately or severely ill on admission as judged by the receiving medical officer, $(f)$ persistently purulent sputum, and $(g)$ a peak respiratory flow rate of $200 \mathrm{l} . / \mathrm{min}$. or less unless too ill to do this.

Patients were excluded who had previous allergy to penicillin, asthma, a known eosinophilia in the sputum of $10 \%$ or more, extensive bronchiectasis, active tuberculosis, carcinoma of the lung, or a blood urea of $60 \mathrm{mg} . / 100 \mathrm{ml}$. or more. Some patients were admitted from home or from other hospitals, and others had acute exacerbations while inpatients in our hospital. Many had not benefited from previous treatments, had protracted illnesses, were severely disabled, and had social problems; so that assessments such as duration of stay in hospital or return to work were valueless. The initial features of the three treatment groups are compared in Table I. Most of these patients were elderly ; two-thirds were moderately and one-third were severely ill on admission, in over half despite previous chemotherapy. The groups were well randomized without significant differences.

TABle I.-Comparability of Antibiotic Groups at Start of Trial

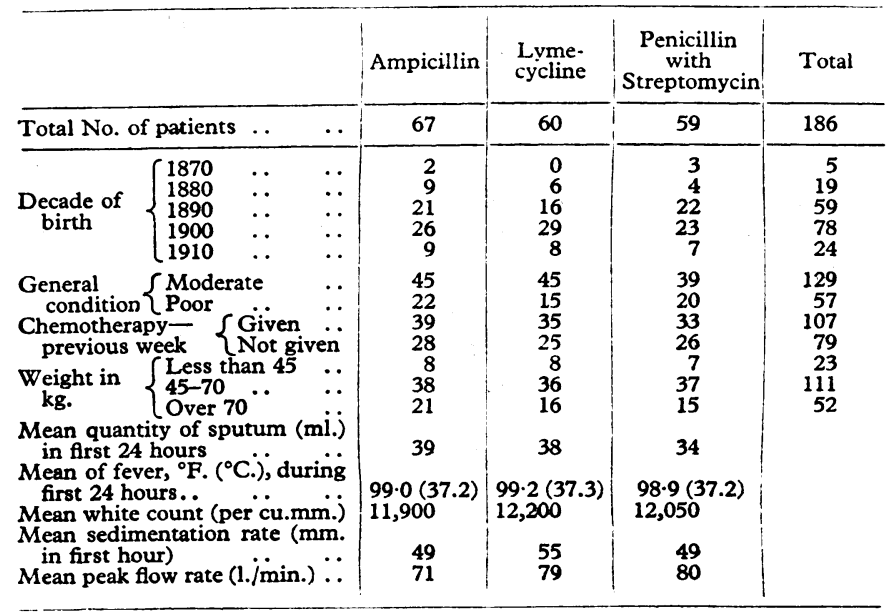

\section{General Treatment}

General treatment included early ambulation, optimistic encouragement, postural drainage, and vigorous physiotherapy when possible, and bronchodilators, copious fluid intake and steam inhalations, and treatment of respiratory or heart failure when indicated.

\section{Results}

Ten patients were withdrawn from the trial and from all analyses, including Table I: one from the ampicillin group, four from the lymecycline group, and five from the penicillinwith-streptomycin group. Of these 10 withdrawals two patients were discovered later to have carcinoma, two pulmonary tuberculosis, and two extensive bronchiectasis; one had an eosinophilia of $20 \%$ in the sputum, and in three the designated treatment was not given. One hundred and eight-six patients were left in the analysis.

\section{Clinical Assessment (Table II)}

Successful or partially successful results were obtained in two-thirds of the patients treated with penicillin and streptomycin and in just over half of those treated with ampicillin or lymecycline. These differences very nearly attain significance at the $5 \%$ level $(P=0.055)$. Few patients deteriorated or died while receiving one of the three antibiotic regimens, in contrast with the placebo-treated patients in the pilot trial.

\begin{tabular}{ll|c|c|c|c}
\multicolumn{7}{c|}{ TABLE II.-General Clinical Assessment } \\
\hline
\end{tabular}

Penicillin with streptomycin, just not significantly better than ampicillin or lymecycline $(P=0.055)$.

\section{Sputum Assessment (Tables III and IV)}

At the end of the seventh day of treatment one-half of those patients given penicillin with streptomycin had achieved mucoid sputum or at the most a trace of pus, but less than half of those given ampicillin or lymecycline. By the fourteenth day of treatment the sputum had become mucoid in two-thirds of those given penicillin and streptomycin but still in less than half of those given ampicillin or lymecycline: the difference is signi-

TABLE III.-State of Sputum on Seventh Day of Treatment

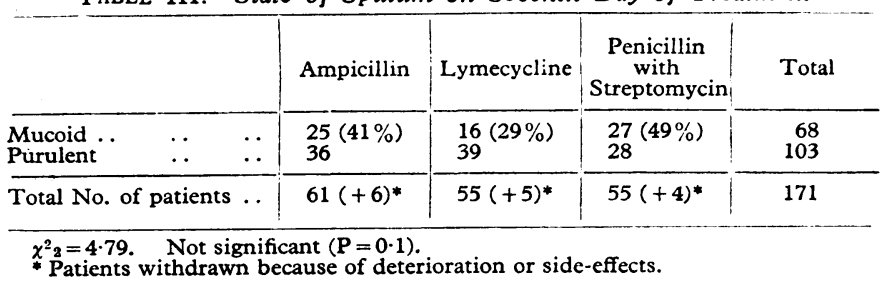

TABLE IV.-State of Sputum on Fourteenth Day of Treatment

\begin{tabular}{|c|c|c|c|c|c|c|}
\hline & & & Ampicillin & Lymecycline & $\begin{array}{c}\text { Penicillin } \\
\text { with } \\
\text { Streptomycin }\end{array}$ & Total \\
\hline $\begin{array}{l}\text { Mucoid .. } \\
\text { Purulent }\end{array}$ & .. & $\therefore$ & $\begin{array}{l}27(47 \%) \\
31\end{array}$ & $\begin{array}{l}23(42 \%) \\
32\end{array}$ & $\begin{array}{l}35(69 \%) \\
16\end{array}$ & $\begin{array}{l}85 \\
79\end{array}$ \\
\hline \multicolumn{3}{|c|}{ Total No. of patients .. } & $58(+9)^{*}$ & $55(+5)^{*}$ & $51(+8)^{*}$ & 164 \\
\hline
\end{tabular}

$\chi^{2} \mathbf{2}=6.56$. Significant $(0.05>\mathrm{P}>0.025)$ for penicillin and streptomycin over

* Patients withdrawn because of deterioration or side-effects. 
ficant at the $5 \%$ level. Lymecycline was less effective than ampicillin in this respect, nor did it reduce the quantity of sputum as much as did ampicillin or penicillin with streptomycin; the differences did not reach the $5 \%$ level of signifcance.

\section{Other Assessments}

The temperature became normal by the third day in all except 10 patients (three, six, and one in each group respectively). T'he white count was still raised after two weeks in 9,11 , and 4 patients of the three treatment groups. Radiographic consolidation was too infrequent for analysis.

The sedimentation rate dropped to a mean 19, 23, and $15 \mathrm{~mm}$. in the first hour by the 15 th day, and the peak flow rate increased by a mean 24,27 , and $39 \%$ respectively. The mean initial $\mathrm{PCO}_{2}$ was 58,59 , and $63 \mathrm{~mm}$. of mercury respectively, falling to 49,50 , and $45 \mathrm{~mm}$. These improvements suggest more effect from penicillin with streptomycin, but none were significant at the $5 \%$ level.

\section{Follow-up}

Nearly all the patients remained in hospital after treatment had ended. An assessment was made at the end of the first week and between the second and fourth weeks, depending on how long the patient stayed in hospital. After one week fivesixths of those given penicillin with streptomycin still had mucoid sputum, as did two-thirds of those receiving lymecycline and just under half of those given ampicillin (Table V). The difference between penicillin with streptomycin and ampicillin was just under the $5 \%$ level of significance. After two to four weeks half of the patients given penicillin with streptomycin still had mucoid sputum, as did over half of those given lymecycline, but only one-sixth of those who had received ampicillin. The differences are significant at the $5 \%$ level (Table VI). Most of the patients whose sputum again became purulent deteriorated clinically at the same time or soon afterwards and had to be given further treatment.

TABle V.-Follow-up on State of Sputum Seven Days After Treatment

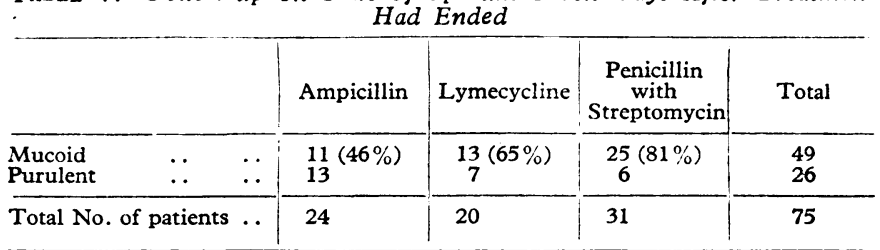
$\chi^{2}=5.82$. Just not significant $(P=0.055)$ for penicillin with streptomycin over lymecycline and ampicillin.

\begin{tabular}{|c|c|c|c|c|c|c|}
\hline & & & Ampicillin & Lymecycline & \begin{tabular}{|} 
Penicillin \\
with \\
Streptomycin
\end{tabular} & Total \\
\hline $\begin{array}{l}\text { Mucoid ... } \\
\text { Purulent }\end{array}$ & 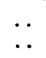 & $\therefore$ & $20(17 \%)$ & $\underset{9}{11}(55 \%)$ & $\begin{array}{l}16(52 \%) \\
15\end{array}$ & $\begin{array}{l}31 \\
44\end{array}$ \\
\hline \multicolumn{3}{|c|}{ Total No. of patients . } & 24 & 20 & 31 & 75 \\
\hline
\end{tabular}

$\chi_{2}^{2}=7.0364$. Significant $(0.05>P>0.025)$ for lymecycline and for penicillin with streptomycin over ampicillin.

\section{Point Scores}

In an attempt to estimate the overall benefit of each regimen points for their agreed clinical importance were awarded or subtracted for (1) improvement or deterioration in clinical state (up to plus 6 or down to minus 6 ); (2) improvement or deterioration in purulence of sputum (up to plus 3 or down to minus 2 ) ; (3) diminution of quantity of sputum (plus 2 to plus 4); (4) maintenance of mucoid sputum one week ( 2 points) and up to four weeks (6 points) later.
At the end of the fortnight's treatment penicillin with streptomycin gained 7.32 mean points per patient against 5.35 for lymecycline and 4.76 for ampicillin, a difference significant at the $5 \%$ level $(\mathrm{P}<0.05)$. When points for the follow-up were included penicillin with streptomycin gained a mean 17.25 points per patient, lymecycline 16.00, and ampicillin 12.67 ; these differences were not significant.

\section{Bacteriology}

The clinical and the laboratory assessments for the presence or absence of pus often disagreed. We have preferred the clinical assessment because (1) the whole 24-hour specimen was assessed in the ward, and (2) inevitable delays in examination in the laboratory might allow the pus to disappear (Medical Research Council, 1965).

At the first examination of the sputum Haemophilus influenzae was found in $29 \%$ of patients. At some time during the trial $H$. influenzae was found in $53 \%$. These results, and those for other potential but more doubtful pathogens, will be analysed elsewhere. Clinical success and the isolation of $H$. influenzae in the initial sputum were not obviously correlated, though this organism was probably responsible for most of the exacerbations (May, 1965).

\section{Side-effects}

Side-effects were noted in 14 patients receiving ampicillin, 10 given lymecycline, and six given penicillin with streptomycin. Nausea, stomach pain, vomiting, and diarrhoea occurred more or less equally among the patients receiving ampicillin or lymecycline (5 and 5, 6 and 2, 5 and 3, and 2 and 4 respectively); previous gastric disorders were reported by four patients in each antibiotic group. Rashes appeared in six patients given ampicillin and in one patient given lymecycline. Because of these side-effects treatment had to be altered in nine patients given ampicillin and in eight given lymecycline. Three patients who had been given penicillin with streptomycin developed rashes and three who were over 70 years of age developed vertigo ; treatment had to be changed in all six patients. Injections of ampicillin were much less painful than those of penicillin with streptomycin or lymecycline, though local anaesthetic was often given with the latter two.

\section{Discussion}

Chronic bronchitis is such a variable disease that it is diffcult to compare individual patients' illnesses. We have restricted our choice of patients for study as much as possible with regard to the most prominent features, such as age, sex, longstanding illness, recent acute exacerbation, general condition, and low respiratory reserve; the presence of purulent sputum was mandatory. Consequently the treatment groups were closely comparable. The clinical and laboratory assessments were quite independent, and bias could not have crept in.

As judged by clinical improvement and clearing of pus from the sputum, penicillin with streptomycin was superior to ampicillin and lymecycline, though reaching statistical significance only in the degree of clearing of the sputum after 14 days of treatment and at the end of the 28 days' follow-up, and in the points score. Benefit in other criteria, especially the peak flow rate and $\mathrm{PCO}_{2}$, also favoured penicillin with streptomycin, but the differences did not reach significant levels-not surprising in our severely and chronically disabled patients.

Ampicillin gave slightly better results than lymecycline during treatment, but was inferior in maintaining improvement during the follow-up, though May and Delves (1964) thought that the bactericidal levels sometimes reached by ampicillin in the sputum, especially during the first days of treatment, 
might give prolonged freedom from purulent relapse. Our findings suggest that penicillin and streptomycin given in high dosage reach sputum concentrations (Zinnemann, 1960 ; Hafez et al., 1965) sufficient to overcome the majority of strains of $H$. influenzae (Turk and May, 1967). Similar findings both in laboratory assays and in patients have been described by Mulder et al. (1952) and by Goslings et al. (1961).

These are overall results and indicate the proportions of patients who could be expected to benefit with each of our antibiotic regimens. Individuals vary in their response: thus some who fail to benefit from penicillin with streptomycin improve with high doses of ampicillin (Pines, 1964). In patients with renal impairment or in those over the age of 70 vestibular toxicity from streptomycin is so frequent that ampicillin or lymecycline is preferable, little difference in side-effects being found between these latter.

Elmes et al. (1965) found that ampicillin gave little advantage over placebo treatment in patients with acute exacerbations of bronchitis. The results of our pilot trial suggest that, on the contrary, it would be unethical not to give antibiotics when such patients are severely ill. Our patients may have had more severe and resistant illnesses. The difference may also reflect the superiority of penicillin with streptomycin to ampicillin. The higher and prolonged dosage of ampicillin we gave seemed more effective than that given by Elmes et al., and certainly better than placebo treatment in the pilot trial. When patients are not so ill chemotherapy may be less beneficialwe are investigating this.

We conclude that penicillin in high doses together with streptomycin is the antibiotic regimen of choice in the management of severe and acute purulent exacerbations of chronic bronchitis, both in ameliorating the infection and in preventing relapse later.

\section{Summary}

Treatment was given to 186 patients with moderate or severe acute exacerbations of chronic bronchitis, the antibiotic regimen being selected at random from penicillin with streptomycin, lyme- cycline (a better-tolerated derivative of tetracycline), or ampicillin, all in high dosage. The clinical results were "blindly" assessed and relevant ventilatory and laboratory data obtained. Penicillin with streptomycin was superior both in immediate results and during the follow-up period of up to one month, significantly so in several respects. Lymecycline and ampicillin were more or less equal to each other.

A pilot trial compared penicillin with streptomycin to a placebo ; unequivocal advantages were shown for those patients given chemotherapy.

We gratefully acknowledge the nursing and secretarial staff of Ware Park Hospital for their help; Dr. W. D. Linsell and the staff of the Pathology Laboratory of the Hertford County and Herts and Essex Hospitals for the laboratory estimations; Dr. J. R. May, Brompton Hospital, for the bacteriological results ; Dr. O. P. Robinson, Beechams Research Laboratories, and Carlo Erba (U.K.) Ltd., for supplies of ampicillin (Penbritin) and lymecycline (Tetralysal) respectively, and for grants towards expenses; Professor J. W. Crofton, University of Edinburgh, for criticism; and the physicians who sent us patients under their care.

\section{REFERENCES}

Elmes, P. C., et al. (1965). Brit. med. 7., 2, 904.

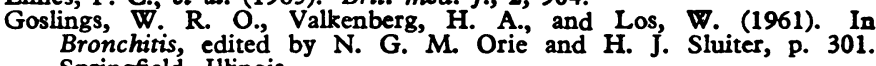
Springfield, Illinois.

Hafez, F. F., Stewart, S. M., and Burnet, M. E. (1965). Thorax, 20, 219.

Johnston, R. N. (1963). In Symposium on Chronic Respiratory Dis-

orders, p. 76. Royal College of Physicians of Edinburgh

May, J. R. (1965). Brit. F. Dis. Chest, 59 57.

May, J. R., and Delves, D. M. (1964). Thorax, 19, 298.

Medical Research Council (1965). Lancet, 1, 775.

Mulder, J., Goslings, W. R. O., van der Plas, M. C., and Lopes Cardozo, P. (1952). Acta med. scand., 143, 32.

Pines, A. (1964). Lancet, 2, 445.

Pines, A., Plucinski, K., Greenfield, J. S. B., and Mitchell, R. C. (1964).

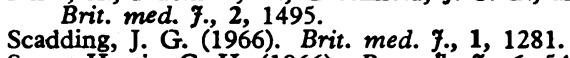

Stuart-Harris, C. H. (1966). Prescrib. Ұ., 6, 54

Turk, D. C., and May, J. R. (1967). Haemophilus Influenzae, p. 73. London.

Wade, O. L. (1967a). Brit. med. 7., 3, 235.

Wade, O. L. (1967b). Postgrad. med.' F., March Suppl., 43, 25.

Zinnemann, K. (1960). Ergebn. Mikrobiol., 33, 307.

\title{
Involuntary Movements in Multiple Sclerosis
}

\author{
N. B. S. SARKARI,* M.D., B.SC., M.R.C.P.ED., M.R.C.P.GLASG.
}

Brit. med. F., 1968, 2, 738-740

Involuntary movements other than tremor, facial myokymia, and flexor spasms are so rarely recognized as a clinical manifestation of multiple sclerosis that no mention of chorea, athetosis, and Parkinsonism in this disease has been discovered in the British literature. Mouren et al. (1966) described one fatal case of hemiballismus due to multiple sclerosis and reviewed five cases from the literature. Four cases of athetosis with lesions of the spinal cord were reported by Balestrieri (1955), one of them being due to multiple sclerosis. Matthews (1958) described four cases showing tonic seizures and suggested that they might represent a central form of tetany. Lance (1963) suggested that these seizures might result from a temporary release of basal ganglia and reticular postural mechanism from cortical control. In view of the rarity of these features it would seem justifiable to describe the cases of three patients clinically suffering from multiple sclerosis in

\footnotetext{
* Midland Centre for Neurosurgery and Neurology, Smethwick, Warley,
}

whom chorea or choreo-athetosis developed during the course of their illness.

\section{Case 1}

The patient was a woman aged 25. Five weeks before admission to hospital on 19 November 1967 she noticed weakness of the right side of the body on rising in the morning, with difficulty in walking and finding the correct words when trying to speak. She would also repeat the same words several times. On examination she had dysphasia, a right hemiplegia, and hypoalgesia of the right side of the body. After a few days during which the weakness increased she began to improve, and in the next two weeks the power returned to the right side. However, she then developed involuntary movements of the right arm and leg. There was no history of headaches, visual disturbance, or fits; she had never had rheumatic fever; she had not been using oral contraceptives; and there was no family history of tremor, involuntary movement, or mental disturbance.

On admission she was euphoric and showed a marked dysarthria but no dysphasia. Both discs were very pale. There was marked 